\title{
Model Design and Evaluation for Recommender System of Smart Schools Implementation Mechanisms
}

\author{
Fereshteh Motahari, ${ }^{1}$ Saeed Rouhani, ${ }^{2,}{ }^{*}$ and Mohammad Amin Zare ${ }^{3}$ \\ ${ }^{1}$ MA, IT Engineering, Mehr Alborz Institute of Higher Education \\ ${ }^{2}$ Assistant Professor, Department of IT Management, Faculty of Management, University of Tehran \\ ${ }^{3}$ Lecturer, Department of IT Management, Mehr Alborz Institute of Higher Education \\ "Corresponding author: Saeed Rouhani, Assistant Professor, Department of IT Management, Faculty of Management, University of Tehran, E-mail: srouhani@ut.ac.ir
}

Received 2015 December 26; Revised 2016 July 30; Accepted 2016 September 30.

\begin{abstract}
Introduction: The implementation of smart schools has significantly progressed in current times due to the execution of intelligent systems. School administrators are also seeking the implementation of smart schools so that they can improve their educational process efficiency. The purpose of this research was to design a system recommending smartening mechanisms for use at the current level, and provide recommendations for improving the quality of schools.

Methods: This is a design science and survey research. The surveyed population consisted of experts in implementing smart schools in the country. Based on convenience accidental sampling method, 32 experts were elected. In this study, previous works on effective factors for the implementation of smart schools were reviewed and categorized. Using the e-learning maturity model and capability maturity model, some questions were prepared and accordingly, the decision tree was drawn in the identified areas. For proper assessment of performance of the recommender system, a QUIS-based questionnaire was developed and experts' opinions were collected through it. For greater certainty and assessment of the face and content validity, the relevant opinions were used. The questionnaire's reliability was calculated using Cronbach's alpha coefficient (92\%). Data analysis was performed using SPSS version 21 and descriptive statistics (mean and SD) as well as inferential statistics (Kolmogorov-Smirnov and Pearson correlation coefficient tests).

Results: The results showed that this system had great potential for improving the implementation quality of smart schools such that the weighted average grades rose above the mean (3.95 to 4.187 of 5) in the assessment.

Conclusions: With regard to the required training criteria, a model was presented and an expert system was designed to recommend mechanisms for implementing smart schools. Finally, this recommender system was evaluated.
\end{abstract}

Keywords: Artificial Intelligence, Education, Schools, Decision Tree

\section{Introduction}

The necessity of using systems recommending mechanisms for implementing smart schools has been proven for updating scientific content and improving the quality of education. In today's world of rapid growth, an increased volume of knowledge and information, rapid aging of teaching material, and swift change and unpredictability of science necessitates education and e-learning rather than traditional education (1). In addition, many of the traditional training methods are inefficient and slow and do not have enough power to convey new concepts to learners. It is therefore necessary to use modern tools created by technologies in this field. One of these tools is information and communication technology (ICT), which has offered many services and advances in the field of education and learning (2). Using new technologies, the smart school project helps to change the old ways and achieve supreme research-based goals of education (3). Smartening schools is a new teaching approach, which has re- sulted in fundamental changes in the teaching-learning process by combining IT and curriculum. In fact, smartening schools is one of the key achievements of IT development in the education sector. This has not only proved effective in the learning environment, but has also been followed by new developments and fundamental reforms in the educational system (4).

Smart School is an e-learning organization designed with the aim of systematic preparation of students to participate in teaching-learning activities and school management. In such schools, providing e-learning services to the students is carried out in-person, and through distance learning. At the same time it maintains a physical environment of a school, teachers, and students, backed by an intelligent educational system and an integrated and comprehensive approach (5). The Smart School is a system with an almost real position and management based on computer technology, network, and electronic content with an intelligent evaluation system and is different from virtual 
schools (6).

In smart schools, students have access to vast information from the web, and in addition to their teacher, they communicate with other teachers and students. Compared to traditional schools, these schools make more use of information technology. The content is presented in an electronic form and the teacher is a guide. In such schools, the problems of traditional teaching methods and educational problems, such as the lack of computer literacy and information literacy are solved with the help of new technology (4).

Given that each school has various capacities regarding technical infrastructure and equipment, staffing, content, software, etc., an appropriate mechanism should be offered for smartening it.

Expert systems are intelligent computer programmes that use knowledge as well as inference and deduction methods to solve problems requiring human skills (7).

The expert system answers questions about specific problems through human deductive inference in knowledge areas where it is specialist.

Expert systems must be able to explain their reasoning and conclusion processes for the end users (8). Due to the ability of expert systems to respond to questions in varying degrees of confidence and the absence of complete information, they are an appropriate tool for use in uncertain conditions or multifaceted environments (9).

A recommender expert system offers appropriate suggestions using the available information and analysing user behaviour and characteristics (10). Obviously, these systems cannot offer suggestions without having sufficient correct information. Hence, one of the fundamental issues is gathering information on different levels of smart schools. Designing an expert system, which can propose the best and most correct mechanism based on available equipment and facilities in various educational systems, seems necessary. Implementation of expert systems will also provide valuable information in making correct decisions about improving the mechanism of implementing smart schools and future planning. The aim of this study was to design a recommender expert system, according to the capacity of each school and provide appropriate smartening mechanisms and suggestions for improving its intelligence level.

Raybad believes that by relying on inductive methods of learning based on training examples, we can build expert systems that are able to work with the most basic knowledge. This knowledge is derived from basic educational examples and the experience gained from collecting new instances during activities. These new examples provide the basis for future learning and generalization steps which are organized as knowledge representation struc- tures (11).

Using batch analysis, Iranmanesh provided software with specifications of expert systems that can break down the big problem of curriculum into several independent problems which involve fewer lessons and professors. In this way, the possibility of using mathematical programming models with reduced constraints and variables is provided (12).

Aram et al. proposed a new approach which develops the knowledge base of an expert system by analysing the electronic problem-solving behaviours of teachers and releases the obtained knowledge. As a result, strict adoption and implementation of the system as a mentor becomes practical for the students and helps them to improve their ability to solve electronic problems (13).

In his study, Aram identified the variables affecting the achievement level of students. Important and influential variables included the general points average (GPA), intelligence, learning, and interest. In this study, an expert system was designed after assessing educational progress dimensions. To design the expert system, we needed to identify the aspects of academic achievement assessment. Therefore, four main variables were considered to evaluate the students in this system. VP Export software was used to do the pilot test (14).

Using Bayesian network, Abbasi presented a method for evaluating and analysing the level of understanding, knowledge, and skills of students in solving problems. Using average $\mathrm{k}$ clustering algorithm, the students were placed at four levels (students with very weak, weak, medium, and high levels of understanding, knowledge and skills) so as to provide them with appropriate recommendations and reports on the progress of students (15).

Sheikhan Sudani designed a system which provided the student with educational content regarding the student's learning style and finally designed a test to assess the student's learning. In order to interact with the student during the training and test, a rule-based expert system was developed in which fuzzy concepts and uncertain factors were used (16).

In his study, Gharabaghi designed an expert system based on nine elements of the Klein Pattern. In this system, the data was first fuzzified and then, the defined rules were entered to the expert system. Defuzzification was done after combining data in the final output system and was used as a basis for judgment (17).

Criteria effective on the recommender system input: were extracted from the literature. The criteria included technical infrastructure and equipment, software, content, human resources, management, and the teachinglearning process. Figure 1 shows the criteria and subcriteria effective on the recommender system input after 
confirmation from experts.

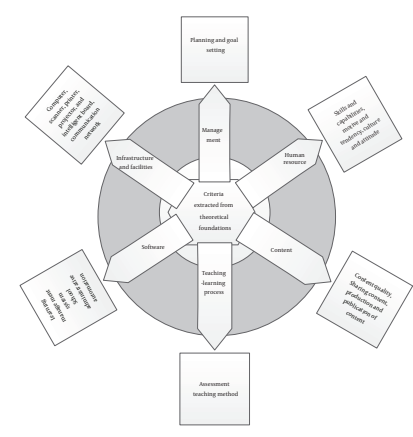

Figure 1. The Criteria and Sub-Criteria Effective on the Recommender System Input

Capability maturity and e-learning maturity models: in order to determine the smart levels of schools, two models of e-learning maturity and capability maturity were used. The capability maturity model is organized in five levels. Multiple sub-criteria are intended at each level of the capability maturity model. It judges the maturity level of the process and introduces key practices or steps required to enhance the functionality or efficiency of the mentioned processes (18). This model is shown in Figure 2.

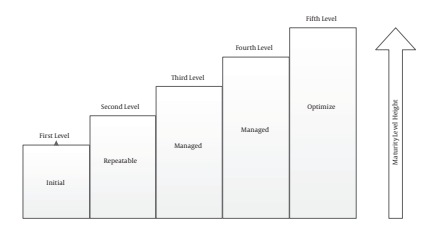

Figure 2. Capability Maturity Model

E-Learning Maturity Model is in accordance with the model proposed by Stephen Marshall and Geoff Mitchell (19). The framework of the e-learning maturity model is given in Table 1.

Table 1. Framework for E-Learning Maturity Model (19)

\begin{tabular}{lc}
\hline Concentration & Level \\
\hline Ad hoc processes & Initial \\
\hline Obvious subject for e-learning & Repeatable \\
\hline $\begin{array}{l}\text { Processes for development } \\
\text { Quality assurance of e-learning resources and student } \\
\text { learning outcomes }\end{array}$ & Defined \\
\hline Continuous improvement & Managed \\
\hline
\end{tabular}

Researchers believe that the capability maturity model and models originating from them can be used in maturity modelling $(20,21)$. In this study, it was necessary to make some changes to the E-learning maturity model to use it. It was thus proportioned according to the characteristics of smart schools. The names of the maturity level were selected according to the general names of the capability maturity model. In describing each of the summary and analysis levels of capability maturity and e-learning maturity models, expert opinions were used. Continuous approach was used to apply the maturity model. In the continuous approach, each process is evaluated separately. Through this approach, it is possible to determine the maturity level for each process and compare the processes of a school with other schools. Based on the raised discussions, the following questions are considered:

1) What smartening solutions should be taken for each school?

2) What are the main criteria for implementing smart schools?

3) What are the various solutions for implementing smart schools based on their attributes?

4) Which model can be used to design the expert system recommending mechanisms for smartening up schools?

\section{Methods}

This is an applied research due to its goal. This study was conducted in two research and operational phases. Therefore, this is a descriptive survey. The Delphi method was used to confirm the system input criteria. This research is quantitative-experimental regarding data analysis.

Cluster sampling was done in a completely random manner from 16 school districts active in the implementation of smart schools. The selected people included a manager and an expert from each district. The population included 32 people who were selected because of their familiarity with the concept of smartening as well as being involved in the implementation of smart schools.

Sampling method was targeted judgment. The research sample in the evaluation and validation part of the recommender expert system consisted of 32 experts out of whom $66 \%$ were male and $34 \%$ were female. About $25 \%$ had doctoral degrees, $41 \%$ held master's degrees, and $34 \%$ had a bachelor's degree. For data collection, library methods such as books, valid scientific papers, and nonlibrary methods like interviews with experts, distribution and analysis of questionnaires were used.

The research process was as follows with the study of internal and external documents and records related to 
the research and interviews with experts. The sets of criteria were defined in six categories of technical infrastructure and facilities, software, content, human resources, management, and teaching-learning processes. The questionnaire was used for evaluation and validation of the recommender expert system. The designed questionnaire was based on the QUIS model. For insuring the validity of the measurement instrument and assessing the content and face validity, opinions of the relevant experts were used. The reliability of the questionnaire was determined as $92 \%$ by calculating Cronbach's alpha.

In order to analyse the research data, descriptive statistics (mean and SD) and inferential statistics (KolmogorovSmirnov and Pearson correlation coefficient) were used in the significance level of 0.05 using SPSS version 21 .

Systemic model: a systemic model of this study involved the preparation and extraction of raw knowledge, design, and production of the recommender system and user interface. The architecture of the recommender system is shown in Figure 3.

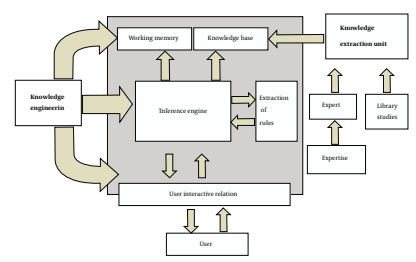

Figure 3. Systemic Model

Extracting knowledge includes the processes of acquisition, organization, and claiming the knowledge of experts as well as library study. The knowledge base and system working memory contain the information obtained in the data acquisition phase and stored in the system using machine language. This knowledge base is generally composed of three main parts:1) rules; 2) statements and 3) actions.

The required rules were extracted using the decision tree. Statements were created by combining two methods of process maturity level and e-learning maturity level; and operations were done based on the continuous method. In rule-based expert systems, the inference engine determines which law should be implemented by existing facts. Of the two general methods of inference, the leading one was used in this recommender expert system as a problem-solving strategy. The inference engine is a technique through which the expert system solves the problems. Using its own logic and rules, this model determines the maturity level of the school and proposes the mechanisms necessary to enhance the quality level. A major part of the systemic model is engineering knowledge. The main goal of knowledge engineering is extraction and classification of the expert's knowledge so as to apply it effectively and efficiently to the expert system.

System evaluation and validation model: the evaluation and validation model of the recommender expert system was a questionnaire based on the QUIS model which used the comments of experts. The questionnaire consisted of two parts: the first part included demographic information and the second part included questions for measuring users' satisfaction of interacting with the recommender expert system based on QUIS standard model (22) as a valid instrument for the assessment and validation of this system. Twenty six questions were designed, six of which were in the first part and the rest in the second part. The questions designed in the second part were placed in the following four categories:

1) General response of the users (five questions)

2) Information display (six questions)

3) Recommender system guide (five questions)

4) Features and capabilities of the recommender system (four questions)

Building the recommender expert system: in order to complete the recommender expert system, the rules on which this system is based must be defined. The decision tree was used to extract the rules. A decision tree is a tree where the samples are classified in such a way that they grow downwards from the roots and eventually reach the leaf nodes. Each internal or non-leaf node is identified with a characteristic feature. This feature raises a question in relation to the proposed expert system. Based on the capability maturity model and e-learning maturity model of the decision tree, the input was separately drawn for six influential criteria. X1 to X6 values were respectively obtained for each of these criteria, including infrastructure and equipment, software, content, human resources, management, and teaching-learning process. To extract the rules of the decision tree based on the continuous approach, the average of selected options was used. In the continuous approach, each process is separately evaluated and it is possible to determine the maturity level for each process. It is also possible to compare the processes of a school with other schools. Around 274 rules were obtained through the decision tree.

The recommender expert system was designed using the programming language visual web developer express. This programming language is considered as one of the most popular tools provided by Microsoft as a simpler alternative to the full version Visual Studio. In this recommender expert system, six main variables of X1 to X6 and an XTotal variable were defined as the main variables of the programme such that the obtained variables at any level 
are placed in them. All rules extracted from the decision tree were codified in the Visual Web Developer Express software. These rules were written as follows.

\section{If (condition 1), then}

Operation 1

End If

The expert system implemented the intended rule based on the question answered by the user. The obtained level was determined based on the criteria of technical infrastructure and equipment, software, content, human resources, management, and teaching-learning process. Based on the obtained levels, the general level of the school is obtained by the following formula

School level $=($ school level in terms of technical infrastructure and equipment + school level in terms of software + school level in terms of content + school level in terms of human resources + school level in terms of management + school level in terms of learning - teaching process)/6.

School smartness level is displayed on the dashboard in the recommender expert system output. Finally, decision tree and the values obtained in each criterion are determined separately. The next coding step includes providing smartening mechanisms. At this stage, the user will receive the mechanisms to promote smartening level by the system after understanding the smartness level of his school. By determining the level of each criterion, the mechanisms that will promote the level of that criterion will be recommended by the system to the user. The user can then be promoted to the next level by observing the proposed mechanisms. After displaying the mechanisms, the user can print the list of solutions in each of the mentioned criteria by selecting the print option. Figure 4 shows a view of the proposed expert system. This system is developed according to the decision tree, which has five levels (based on five criteria) and each level has five stages (based on Capability Maturity Model). The combinations of those criteria and these maturity stages have produced 274 rules $\left(R_{1} \ldots R_{n}\right)$.

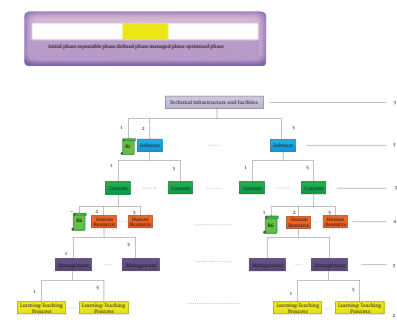

Figure 4. Conceptual Model of the Proposed Expert System

\section{Results}

To test the normality of the assessment variables, the Kolmogorov-Smirnoff test was used. The test results showed that the significance level is larger than 0.05 . Hence, all criteria are normally distributed. The results are shown in Table 2.

Table 2. Results of the Kolmogorov-Smirnov Test

\begin{tabular}{lccc}
\hline $\begin{array}{l}\text { Expert System Evaluation } \\
\text { Criteria }\end{array}$ & No. & Test Statistic & Significance Level \\
\hline $\begin{array}{l}\text { The general reaction of } \\
\text { users }\end{array}$ & 32 & 1.017 & 0.253 \\
\hline $\begin{array}{l}\text { Information screen } \\
\text { Recommender System }\end{array}$ & 32 & 1.338 & 0.056 \\
$\begin{array}{l}\text { Guide } \\
\begin{array}{l}\text { Features and functionality } \\
\text { of the recommender } \\
\text { system }\end{array}\end{array}$ & 32 & 1.726 & 0.187 \\
\hline
\end{tabular}

To investigate the correlation between the expert system evaluation criteria, the significance level of each criterion was calculated separately with other criteria at 0.05 . The results showed that the correlation coefficient between criteria had a probability less than the significance level of 0.05 . So, there is a significant positive correlation between these criteria. Correlation between the criteria was calculated using Pearson correlation coefficient and the results are shown in Table 3.

The weighted average of evaluation criteria was calculated separately. The weighted average of the criteria in order of importance included the information display, recommender system guide, features and functionalities of the recommender system, and general response of the users. Figure 5 shows the weighted average of the evaluation criteria of the recommender expert system.

The analysis results are summarized in Figure 6. On the one hand, the average scores of each criterion and on the other hand, the relationships between criteria are shown. As specified, the correlation coefficient between the studied criteria is positive and significant at the level of 0.05. Results of the assessment of the recommender system showed that all indicators of the designed system have gained an above average score.

\section{Discussion and Conclusions}

Today, the rapid progress of information technology and e-learning has resulted in an increasing smartening of schools. It is evident that providing the mechanisms effective in implementing smart schools is essential. In this study, with regard to the required educational criteria, an 
Table 3. Correlation Between the Criteria

\begin{tabular}{|c|c|c|c|c|c|}
\hline $\begin{array}{l}\text { Correlation Expert } \\
\text { System Evaluation } \\
\text { Criteria }\end{array}$ & $\begin{array}{c}\text { Correlation } \\
\text { Coefficient }\end{array}$ & $\begin{array}{c}\text { General Reaction of } \\
\text { Users }\end{array}$ & Information Display & $\begin{array}{c}\text { Recommender System } \\
\text { Guide }\end{array}$ & $\begin{array}{c}\text { Recommender System } \\
\text { Features and } \\
\text { Functionality }\end{array}$ \\
\hline \multirow{2}{*}{$\begin{array}{l}\text { Overall reaction of } \\
\text { users }\end{array}$} & Correlation coefficient & 1 & 0.712 & 0.703 & 0.795 \\
\hline & Significance level & - & 0.005 & 0.004 & 0.001 \\
\hline \multirow{2}{*}{ Screen Information } & Correlation coefficient & & 1 & 0.672 & 0.789 \\
\hline & Significance level & & - & 0.009 & 0.002 \\
\hline \multirow{2}{*}{$\begin{array}{l}\text { Recommender system } \\
\text { guide }\end{array}$} & Correlation coefficient & & & 1 & 0.000 \\
\hline & Significance level & & & - & 1 \\
\hline \multirow{2}{*}{$\begin{array}{l}\text { Recommender system } \\
\text { features and } \\
\text { capabilities }\end{array}$} & Correlation coefficient & & - & & 0.002 \\
\hline & Significance level & & & & \\
\hline
\end{tabular}

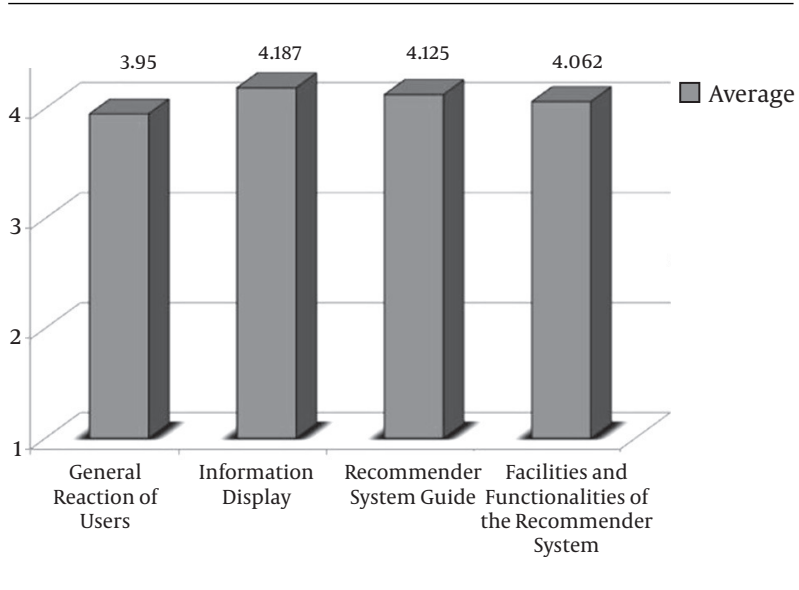

Figure 5. Weighted Average of the Evaluation Criteria of the Recommender Expert System

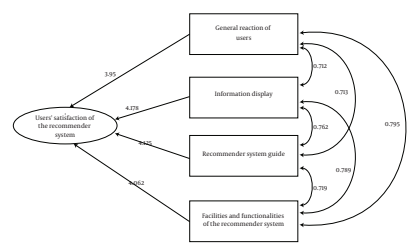

Figure 6. Information Analysis Summary

expert system has been designed which can offer mechanisms for implementing smart schools.

The study of the criteria for smartening schools in different scientific sources and recent research has been case specific and sporadic. Abdul Wahabi et al. investigated the criteria effective in smartening schools regarding attitude, culture, management, financial resources, performance, and computer literacy (3). Khezrlu studied the criteria of technical infrastructure and equipment, and teachinglearning process (23). Keong et al. also examined the technical infrastructure and equipment, software, and human resources (24).

In this study, after a careful study and collection of all criteria effective in implementing smart schools, some criteria were selected as the input of the system recommending solutions. The criteria included six main criteria and 14 sub-criteria which were extracted from the literature and expert opinions and considered as the input of the expert system. The main criteria included technical infrastructure and equipment, software, content, human resources, management, and teaching-learning process.

In this study, a multi-level maturity model has been suggested and customized for the classification of smart schools. This has added new criteria to the research literature. The model includes the initial, repeatable, defined, managed, and optimized phases. The criteria of technical infrastructure and equipment, software, content, human resources, management and teaching-learning process were studied in it.

Based on the maturity model, a recommender expert system was designed and implemented. Users of this system are the managers or officials of implementing smart schools who will smarten up their school in two separate stages. In the first stage, according to the existing criteria, the current smartness level of the school will be determined. In the second stage, appropriate functional mechanisms will be recommended for promoting the smartness level. In fact, this system greatly helps school administrators and experts in decision-making and functional planning. Then, based on the smartness level of the school, mechanisms to improve smartness levels are 
recommended by the software. In designing the recommender expert system, the relationship between the user and the system has been considered as the relationship between the user and the expert. In other words, presentation and exchange of the required smartening information between the expert system and the user are of high power.

To design the recommender expert system, Raybad (11) relied on inductive methods of learning; Abbasi (15) used Bayesian network, Sheikhan Sudani (16) used fuzzy concepts and certainty factor; and Aram (14) made use of VP Export software. In this study, a series of rules were extracted to design the recommender expert system with the use of the decision tree inspired by capability maturity and e-learning maturity models and was designed with the programming language visual web developer express. Compared to previous studies, the most important advantage of this programming language was the online expert system and its user friendliness.

The system was validated according to the requirements of real users. It was experimentally evaluated and validated by the experts after being designed and placed on the internet. Accordingly, these people gave their opinions by filling a comprehensive questionnaire covering all aspects of this system. Finally, the average weight of each criterion was calculated. Evaluation and validation results showed that this system has high potential and functionality in decision-making and executive planning for implementation of smart schools in the best way possible. According to them, the highest averages respectively included the criteria of information display, recommender system guide, features and functionalities of the recommender system, and the overall response of users.

It is recommended that the implementation of this software should be executed in an educational place, such as a school or an educational institution to determine its applicability level. It is also recommended that future researchers implement the new technologies of the educational system in the recommender expert system because in the new educational system, learning technologies are considered as the main basis of education.

\section{Acknowledgments}

The authors would like to thank the editors and the two anonymous reviewers for a very constructive and developmental review process. The authors also thank the University of Tehran and Mehralborz University.

\section{Footnotes}

Authors' Contribution: Idea: Dr. Saeed Rouhani; study concept and Model design: Fereshteh Motahari and Mohammad Amin Zare; system development: Fereshteh Motahari; analysis and interpretation of data: Fereshteh Motahari, Mohammad Amin Zare and Dr. Saeed Rouhani; drafting of the manuscript: Fereshteh Motahari; critical revision of the manuscript: Fereshteh Motahari and Dr. Saeed Rouhani.

Conflict of Interest: This research has no potential conflict of interest and did not gain any third party sponsorship.

\section{References}

1. Yaghma A. Demand for change in the education system. The growth of educational technology. ; 2006.

2. Nourozi M, Zandi F, Mousavi Madani F. Ranking of IT application in teaching-learning process in schools. J Educ Innov. 2004;7(26):145-56.

3. Abdulvahabi M, Mehr Alizade Y, Parsa A. The possibility of establishing schools for girls in secondary schools in Ahvaz. J Educ Innov. 2008;11(43):181-12.

4. Niromand G, Yazdani H, Ganji D. Review of information and communication technology and implementation requirements and the development of smart schools in Iran. The first Conference of intelligent computer systems and applications. PNU; .

5. Anderson T. The theory and practice of online learning. Athabasca University Press; 2008.

6. Zamani B. Integration of ICT in Education.J Educ. 2007;1(12):4-11.

7. Taleghani H. Artificial intelligence 2014. Available from: http:// artificial-i.blogfa.com/cat-2.aspx.

8. O'Brien C. Sustainable production - a new paradigm for a new millennium. Int JProd Econ. 1999;60-61:1-7. doi:10.1016/s0925-5273(98)001261 .

9. Massingham P. Linking business level strategy with activities and knowledge resources. J Knowledge Manag. 2004;8(6):50-62. doi: $10.1108 / 13673270410567620$

10. Ozbal G, Karaman H. Matchbook a web based recommendation system for matchmaking. 23rd International Symposium on Computer and Information Sciences. .

11. Rybod R. The study, design and implement a production environment expert systems educable. Tehran: Sharif University; 1993.

12. Iranmanesh C. Designing an expert system for planning university education. Tehran: Sharif University; 1995.

13. Aram S, Sadri M, Hassanzadeh M. Performance Evaluation of Webbased education expert systems and its impact Brtshyl student learning performance. The First Conference of intelligent computer systems and applications. Tehran. PNU; .

14. Aram S. Providing an expert system for evaluating academic achievement and student success. Tehran: PNU; 2013.

15. Abbasi K. Learning model and student model in intelligent training system. Sistan-Baluchistan: University of Sistan-Baluchistan; 2013.

16. Sheykhan Sudani L. Design and implementation of intelligent user interfaces in peripheral intelligence emotional education system. University of shaykh Bahaee; 2014.

17. Gharabaghi $\mathrm{H}$. The use of expert systems and fuzzy logic rules for assessing the quality of educational technology curriculum at graduate and doctoral universities in the state, according to Klein model and software quality analysis program, a DVSc the end of the, Allameh Tabatabaei University. ; 2015. 
18. Paulk MC.A history of the capability maturity model for software.ASQ Software Qual Professional. 2009;12(1):5-19.

19. Marshall S, Mitchell G. An e-learning maturity model. Proceedings of the 19th Annual Conference of the Australian Society for Computers in Learning in Tertiary Education. New Zealand. Citeseer; .

20. Paulzen O, Doumi M, Perc P, Cereijo-Roibas A. A maturity model for quality improvement in knowledge management. ACIS 2002 Proceedings. .

21. Armour PG. The Business of Software: the case for a new business model. Commun ACM. 2000;43(8):19-22. doi:10.1145/345124.345131.
22. Norman DA. The invisible computer: why good products can fail, the personal computer is so complex, and information appliances are the solution. MIT press; 1998.

23. Khezerlu H. . Factors influencing the trend elementary teachers to use educational media in teaching and learning process of teachers in the city of Urmia, summary report 40 research projects and theses, research institutes curricula and educational innovation. ;2001.

24. Keong CC, Horani S, Daniel J. A study on the use of ICT in mathematics teaching. Malaysian Online J Instruct Technol. 2005;2(3):43-51. 